\title{
Analysis of geographic and pairwise distances among sheep populations
}

\author{
J.B. Liu ${ }^{1}$, Y.J. Yue ${ }^{1}$, X. Lang' ${ }^{1}$ F. Wang ${ }^{2}$, X. Zha ${ }^{3}$, J. Guo ${ }^{1}$, R.L. Feng ${ }^{1}$, \\ T.T. Guo ${ }^{1}$, B.H. Yang ${ }^{1}$ and X.P. Sun ${ }^{1}$ \\ ${ }^{1}$ Lanzhou Institute of Husbandry and Pharmaceutical Sciences of Chinese \\ Academy of Agricultural Sciences, Lanzhou, China \\ ${ }^{2}$ Lanzhou Veterinary Research Institute of Chinese Academy of Agricultural \\ Sciences, China Agricultural Veterinarian Biology Science and Technology Co. Ltd., \\ Lanzhou, China \\ ${ }^{3}$ Institute of Livestock Research, Tibet Academy of Agriculture and Animal Science, \\ Lhasa, China \\ Corresponding author: X.P. Sun \\ E-mail: sunxiaoping163@163.com
}

Genet. Mol. Res. 13 (2): 4177-4186 (2014)

Received January 30, 2013

Accepted July 5, 2013

Published June 9, 2014

DOI http://dx.doi.org/10.4238/2014.June.9.4

\begin{abstract}
This study investigated geographic and pairwise distances among seven Chinese local and four introduced sheep populations via analysis of 26 microsatellite DNA markers. Genetic polymorphism was rich, and the following was discovered: 348 alleles in total were detected, the average allele number was 13.38 , the polymorphism information content (PIC) of loci ranged from 0.717 to 0.788 , the number of effective alleles ranged from 7.046 to 7.489 , and the observed heterozygosity ranged from 0.700 to 0.768 for the practical sample, and from 0.712 to 0.794 for expected heterozygosity. The Wright's $F$-statistic of subpopulations within the total $\left(F_{\mathrm{ST}}\right)$ was 0.128 , the genetic differentiation coefficient $\left(G_{\mathrm{ST}}\right)$ was 0.115 , and the average gene flow $\left(N_{\mathrm{m}}\right)$ was 1.703 . The phylogenetic trees based on the neighbor-joining method by Nei's genetic distance $\left(D_{\mathrm{A}}\right)$ and Nei's standard genetic distance $\left(D_{\mathrm{S}}\right)$ were similar. Sheep populations clustered
\end{abstract}


into group 1 (Ta, M, L, H, O, G, and Q breeds) and group 2 (PD, WS, B, and $\mathrm{T}$ breeds). These results will have an important value applied and directive significance for sheep breeding in the future.

Key words: Sheep; Geographic distance; Pairwise distance; Genetic diversity

\section{INTRODUCTION}

Sheep breeding plays an important role in Chinese animal agriculture, particularly in underdeveloped, rural, and mountain areas where production systems are based on local or native breeds. Therefore, it is of great importance to conserve genetic resources for the maintenance of more extensive breeding options. Assessment of genetic variability in domestic sheep is the first step toward this genetic resource conservation. Phylogenetic studies of population diversification have led to the identification of the essential features of many species' evolutionary histories. The intensification of production systems combined with successes in industrial breeding has led farmers to abandon certain native breeds. Additionally, domesticated animals are currently losing genetic diversity due to several other factors. First, intensive selection of highly productive breeds has placed inadequate emphasis on the preservation of overall genetic diversity. Second, native breeds in marginal areas are facing extinction, and little or no action is being taken to reverse this trend (Taberlet et al., 2008). Microsatellites provide accurate genetic information about individual genotypes and genetic relationships between populations (Arranz et al., 1998; Ruane, 1999; Kantanen et al., 2000). However, the efficiencies of distance measures in phylogenetic reconstruction using microsatellite data compared to traditional distance metrics remain unknown. Calculation of genetic distances from microsatellite data can provide useful information for the monitoring and management of genetic diversity of rare breeds.

To date, many studies have indicated that microsatellite markers could be used to analyze genetic diversity and genetic structure across several species, including sheep (Gaouar et al., 2012), goat (Bindu et al., 2012), cattle (Azam et al., 2012), deer (Colson et al., 2012), monkey (Chang et al., 2012), and chicken (Leroy et al., 2012) among others. The aim of this study was to assess the usefulness of microsatellite polymorphisms for the analysis of the genetic relationships among seven Chinese local and four introduced sheep breeds. The results of this analysis will help to understand the genetic relationships among sheep breeds.

\section{MATERIAL AND METHODS}

\section{Animals and DNA samples}

Four introduced sheep breeds and seven Chinese local sheep breeds were selected for this study. Ten milliliter of blood samples were collected from the jugular vein of each animal. From the $10 \mathrm{~mL}$ samples, $2 \mathrm{~mL}$ samples were quickly frozen in liquid nitrogen and stored at $-80^{\circ} \mathrm{C}$ for genomic DNA extraction, as described previously (d'Angelo et al., 2006). Total DNA was extracted from whole blood using the saturated salt method (Sambrook et al., 1989), quantified spectrophotometrically, and adjusted to $50 \mathrm{ng} / \mu \mathrm{L}$. The blood samples were collected from 1280 sheep that were not directly related. The sampled individuals belonged to the eleven sheep 
populations that are distributed across Gansu Province and Qinghai Province. In order to ascertain the historical relationships and relative genetic contributions among populations, the genetic characteristics of these sheep breeds were analyzed. The above-described breeds included the following numbers and corresponding breed types: 98 White Suffolk (WS), 98 Borderdale (B), 218 Poll Dorset (PD), 84 Texel (T), 135 Small Tail Han sheep (H), 112 Mongolian sheep (M), 118 Tan sheep (Ta), 80 Lanzhou Large Tailed sheep (L), 132 Oula (O), 95 Ganjia (G), and 110 Qiaoke sheep (Q), which were all raised in the Gansu and Qinghai provinces in China (Table 1).

Table 1. Name, code, sample size, and source region of eleven sheep populations.

\begin{tabular}{|c|c|c|c|c|}
\hline \multirow[t]{2}{*}{ Population } & \multirow[t]{2}{*}{ Population code } & \multicolumn{2}{|c|}{ Sample number } & \multirow[t]{2}{*}{ Sampling location } \\
\hline & & $\hat{0}$ & q & \\
\hline White Suffolk & WS & 16 & 82 & $\begin{array}{l}\text { Yongchang county breeder sheep farm and Lanzhou city Xinghe } \\
\text { breeder sheep farm, Gansu Province }\end{array}$ \\
\hline Borderdale & $\mathrm{B}$ & 21 & 77 & Yongchang county breeder sheep farm, Gansu Province \\
\hline Poll Dorset & $\mathrm{PD}$ & 34 & 184 & $\begin{array}{l}\text { Yongchang county breeder sheep farm and Lanzhou city Xinghe } \\
\text { breeder sheep farm, Gansu Province }\end{array}$ \\
\hline Texel & $\mathrm{T}$ & 20 & 64 & Yongchang county breeder sheep farm, Gansu Province \\
\hline Small-tail Han sheep & $\mathrm{H}$ & 28 & 107 & Dingxi and Longxi County, Gansu Province \\
\hline Mongolian sheep & $\mathrm{M}$ & 14 & 98 & Mongolian and Yugu Autonomous County, Gansu Province \\
\hline Tan sheep & $\mathrm{Ta}$ & 36 & 82 & Gaolan, Jingtai, and Jingyuan County, Gansu Province \\
\hline Lanzhou Large-tailed sheep & $\mathrm{L}$ & 8 & 72 & Lanzhou City, Gansu Province \\
\hline Oula sheep & $\mathrm{O}$ & 38 & 94 & $\begin{array}{l}\text { Maqu County, Gansu Province, and Henan County, Qinghai } \\
\text { Province }\end{array}$ \\
\hline Ganjia sheep & G & 9 & 86 & Xiahe County, Gansu Province \\
\hline Qiaoke sheep & Q & 18 & 92 & Maqu and Luqu County, Gansu Province \\
\hline
\end{tabular}

\section{Primer design and PCR amplification}

Primers flanking 26 microsatellite loci located in several different chromosomes were designed based on an available genome sequence (Table 2) (Crawford et al., 1995) and synthesized by the Shanghai Shenggong Biological Engineering Company. Polymerase chain reaction (PCR) was carried out in a $25 \mu \mathrm{L}$ reaction system containing $2 \mu \mathrm{L}$ genomic DNA template, $1.5 \mu \mathrm{L} 25 \mathrm{mM} \mathrm{MgCl}_{2}, 2 \mu \mathrm{L} 10 \mathrm{mM}$ dNTP, $0.25 \mu \mathrm{L} 5 \mu \mathrm{L} / \mathrm{U}$ Taq DNA polymerase (TaKaRa, China), $2 \mu \mathrm{L} 8 \mathrm{pM}$ each forward and reverse primer, $2.5 \mu \mathrm{L}$ 10X PCR buffer, and $\mathrm{ddH}_{2} \mathrm{O}$ (up to $25 \mu \mathrm{L}$ ). PCR conditions were as follows: initial denaturation for $5 \mathrm{~min}$ at $94^{\circ} \mathrm{C}$, 35 cycles at $94^{\circ} \mathrm{C}$ for $1 \mathrm{~min}$, annealing temperatures at $52^{\circ}-58^{\circ} \mathrm{C}$ for $40 \mathrm{~s}$, and extension at $72^{\circ} \mathrm{C}$ for $40 \mathrm{~s}$. The final extension step was followed by a 5 min extension at $72^{\circ} \mathrm{C}$.

\section{DNA sequencing and agarose electrophoresis analysis}

For analysis, $2 \mu \mathrm{L}$ PCR product was mixed with $6 \mu \mathrm{L}$ denaturing solution $(95 \%$ formamide, $25 \mathrm{mM}$ ethylenediaminetetraacetic acid, $0.025 \%$ xylene cyanol, and $0.025 \%$ bromophenol blue), heated for $10 \mathrm{~min}$ at $98^{\circ} \mathrm{C}$, and chilled on ice. The electrophoresis was run at 250 $\mathrm{V}$ and $40 \mathrm{~mA}$ (pre-electrophoresis) for $10 \mathrm{~min}$, followed by $150 \mathrm{~V}$ and $24 \mathrm{~mA}$ (Kucharczyk Techniki Elektroforetyczne) for $8 \mathrm{~h}$ with silver staining. A refrigerated circulator was used to control the gel temperature $\left(4^{\circ} \mathrm{C}\right)$. Then, each locus of the number of alleles was computed using the Excel Microsatellite Toolkit (Version 3.1) software. Fragment lengths of PCR products were determined using the GeneMapper software (Version 3.7). 
Table 2. Information for the 26 microsatellite loci.

\begin{tabular}{|c|c|c|c|c|c|}
\hline Locus & Chromosome & Primer sequence (5'-3') & Allele number & $\begin{array}{c}\text { Annealing } \\
\text { temperature }\left({ }^{\circ} \mathrm{C}\right)\end{array}$ & $\begin{array}{c}\text { Fragments } \\
\text { size }\end{array}$ \\
\hline \multirow[t]{2}{*}{ BM6506 } & 1 & GCACGTGGTAAAGAGATGGC & & & \\
\hline & & AGCAACTTGAGCATGGCAC & 12 & 58 & $190-212$ \\
\hline \multirow[t]{2}{*}{ OarFCB128 } & 2 & ATTAAAGCATCTTCTCTTTATTTCCTCGC & & & \\
\hline & & CAGCTGAGCAACTAAGACATACATGCG & 13 & 58 & $94-126$ \\
\hline \multirow[t]{2}{*}{ OarFCB20 } & 2 & AAATGTGTTTAAGATTCCATACAGTG & & & \\
\hline & & GGAAAACCCCCATATATACCTATAC & 13 & 56 & $90-112$ \\
\hline \multirow[t]{2}{*}{ OarCP34 } & 3 & GCTGAACAATGTGATATGTTCAGG & & & \\
\hline & & GGGACAATACTGTCTTAGATGCTGC & 12 & 54 & $100-128$ \\
\hline \multirow[t]{2}{*}{ BM827 } & 3 & GGGCTGGTCGTATGCTGAG & & & \\
\hline & & GTTGGACTTGCTGAAGTGACC & 14 & 58 & $212-228$ \\
\hline \multirow{2}{*}{ OarHH35 } & 4 & AATTGCATTCAGTATCTTTAAACATCTGGC & & & \\
\hline & & ATGAAATATAAAGAGAATGAACCACACGG & 14 & 56 & $118-140$ \\
\hline \multirow{2}{*}{ OarJMP8 } & 6 & CGGGATGATCTTCTGTCCAAATATGC & & & \\
\hline & & CATTTGCTTTGGCTTCAGAACCAGAG & 16 & 58 & $115-153$ \\
\hline \multirow{2}{*}{ BM757 } & 9 & TGGAAACAATGTAAACCTGGG & & & \\
\hline & & TTGAGCCACCAAGGAACC & 11 & 58 & $176-190$ \\
\hline \multirow{2}{*}{ OarHH41 } & 10 & TCCACAGGCTTAAATCTATATAGCAA & & & \\
\hline & & GAGCGGTGTAGTAGAAAATAGAAATCGACC & 15 & 58 & $120-147$ \\
\hline \multirow{2}{*}{ OarCP38 } & 10 & CAACTTTGGTGCATATTCAAGGTTGC & & & \\
\hline & & GCAGTCGCAGCAGGCTGAAGAGG & 12 & 58 & $79-119$ \\
\hline \multirow[t]{2}{*}{ HUJ616 } & 13 & TTCAAACTACACATTGACAGGG & & & \\
\hline & & GGACCTTTGGCAATGGAAGG & 17 & 56 & $131-196$ \\
\hline \multirow[t]{2}{*}{ ILSTS002 } & 14 & TCTATACACATGTGCTGTGC & & & \\
\hline & & CTTAGGGGTGAAGTGACACG & 14 & 54 & $131-161$ \\
\hline \multirow[t]{2}{*}{ RM004 } & 15 & CAGCAAAATATCAGCAAACCT & & & \\
\hline & & CCACCTGGGAAGGCCTTTA & 12 & 58 & $140-156$ \\
\hline \multirow[t]{2}{*}{ MAF65 } & 15 & AAAGGCCAGAGTATGCAATTAGGAG & & & \\
\hline & & ССАСТССТССТGAGAATATAACATG & 11 & 52 & $111-139$ \\
\hline \multirow[t]{2}{*}{ OarFCB48 } & 17 & GACTCTAGAGGATCGCAAAGAACCAG & & & \\
\hline & & GAGTTAGTACAAGGATGACAAGAGGCAC & 10 & 58 & $140-156$ \\
\hline \multirow[t]{2}{*}{ BM8125 } & 17 & СТСТATCTGTGGAAAAGGTGGG & & & \\
\hline & & GGGGGTTAGACTTCAACATACG & 10 & 58 & $110-124$ \\
\hline \multirow[t]{2}{*}{ OarHH47 } & 18 & TTTATTGACAACTCTCTTCCTAACTCCACC & & & \\
\hline & & GTAGTTATTTAAATATCATACCTCTTAAGG & 17 & 56 & $129-156$ \\
\hline \multirow[t]{2}{*}{ OarFCB304 } & 19 & CCCTAGGAGCTTTCAATAAAGAATCGG & & & \\
\hline & & CGCTGCTGTCAACTGGGTCAGGG & 15 & 56 & $151-179$ \\
\hline \multirow[t]{2}{*}{ OarAE119 } & 19 & CTCAGCAAATGGTTCCTGGGGACC & & & \\
\hline & & TTTTATAGTGAGGTGACCACTTGATG & 13 & 56 & $147-185$ \\
\hline \multirow[t]{2}{*}{ OMHC1 } & 20 & ATCTGGTGGGCTACAGTCCATG & & & \\
\hline & & GCAATGCTTTCTAAATTCTGAGGAA & 11 & 58 & $130-159$ \\
\hline OarCP20 & 21 & GATCCCCTGGAGGAGGAAACGG & & & \\
\hline & & GGCATTTCATGGCTTTAGCAGG & 15 & 56 & $76-102$ \\
\hline BM1314 & 22 & ТTССТССТСТТСТСТССААAC & & & \\
\hline & & ATCTCAAACGCCAGTGTGG & 12 & 54 & $137-161$ \\
\hline CSSM31 & 23 & CCAAGTTTAGTACTTGTAAGTAGA & & & \\
\hline & & GACTCTCTAGCACTTTATCTGTGT & 18 & 58 & $118-151$ \\
\hline OarJMP29 & 24 & GTATACACGTGGACACCGCTTTGTAC & & & \\
\hline & & GAAGTGGCAAGATTCAGAGGGGAAG & 11 & 58 & $88-134$ \\
\hline OarVH72 & 25 & GGCCTCTCAAGGGGCAAGAGCAGG & & & \\
\hline & & CTCTAGAGGATCTGGAATGCAAAGCTC & 15 & 56 & $125-165$ \\
\hline BM6526 & 26 & CATGCCAAACAATATCCAGC & & & \\
\hline & & TGAAGGTAGAGAGCAAGCAGC & 15 & 56 & $161-175$ \\
\hline
\end{tabular}

\section{Statistical Analysis}

Gene and genotypic frequencies were estimated via direct gene counting. The allelic number $\left(N_{\mathrm{A}}\right)$, number of effective alleles $\left(N_{\mathrm{E}}\right)$, private allele number $\left(P_{\mathrm{A}}\right)$, expected heterozygosity $\left(H_{\mathrm{E}}\right)$, observed heterozygosity $\left(H_{\mathrm{O}}\right)$, polymorphic information content (PIC), and allelic 
richness (AR) were estimated using the POPGENE software (version 1.31). The significance of the $F$-statistics was determined from permutation tests in which the sequential Bonferroni procedure was applied over loci (Hochberg, 1988). The $F$-statistics indices were computed using the FSTAT program. The estimate for gene flow $\left(N_{\mathrm{m}}\right)$ was based on the following relationship: $N_{\mathrm{m}}=0.25\left(1-F_{\mathrm{ST}}\right) / F_{\mathrm{ST}}$, where $F_{\mathrm{ST}}$ was the mean $F_{\mathrm{ST}}$ value across all loci (Slatkin and Barton, 1989). Reynolds' genetic distance between breeds was calculated based on the $F_{\mathrm{ST}}$ values (Reynolds et al., 1983). A consensus neighbor-joining (NJ) dendrogram of the eleven sheep populations, based on Nei's genetic distances $\left(D_{\mathrm{S}}\right)$, was reconstructed using the DISPAN software (version 1.1); this was the most effective way to obtain accurate phylogenetic trees (Takezaki and Nei, 1996). $G_{\mathrm{ST}}$ was calculated based on data from all loci (Takezaki et al., 2010).

\section{RESULTS}

\section{Genetic diversity}

Tables 2 and 3 display the following data: a description of the markers, including chromosomal localization, number of alleles per marker, fragment size, observed and expected heterozygosities, and genetic variation for the 26 microsatellite loci used. The 26 microsatellites had 348 alleles, and the mean number of alleles per locus in the population was 13.38. Most of the markers used had allele number values higher than 13, but they ranged from 10 (OarFCB48 and BM8125) to 18 (CSSM31) alleles per marker (Table 2).

\section{Table 3. Genetic variation in the eleven sheep populations.}

\begin{tabular}{|c|c|c|c|c|c|c|c|}
\hline \multirow[t]{2}{*}{ Population } & \multicolumn{3}{|c|}{ Allelic diversity } & \multicolumn{4}{|c|}{ Genetic diversity } \\
\hline & $N_{\mathrm{A}}$ & $N_{\mathrm{E}}$ & $P_{\mathrm{A}}$ & $H_{\mathrm{E}}$ & $H_{\mathrm{o}}$ & PIC & $A R$ \\
\hline$\overline{\mathrm{WS}}$ & 8.7367 & 7.1479 & 0 & 0.7118 & 0.7032 & 0.7639 & 7.1060 \\
\hline B & 8.6725 & 7.1350 & 0 & 0.7297 & 0.7131 & 0.7612 & 7.1969 \\
\hline PD & 8.6200 & 7.2901 & 0 & 0.7163 & 0.7016 & 0.7568 & 7.0856 \\
\hline $\mathrm{T}$ & 8.6241 & 7.2047 & 0 & 0.7227 & 0.7179 & 0.7641 & 7.2042 \\
\hline $\mathrm{H}$ & 9.4750 & 7.4753 & 1 & 0.7942 & 0.7676 & 0.7879 & 7.6930 \\
\hline M & 8.6000 & 7.2091 & 0 & 0.7726 & 0.7433 & 0.7642 & 7.5103 \\
\hline $\mathrm{Ta}$ & 9.2564 & 7.2929 & 0 & 0.7611 & 0.7214 & 0.7539 & 7.4198 \\
\hline $\mathrm{L}$ & 8.2000 & 7.4894 & 2 & 0.7812 & 0.7640 & 0.7412 & 7.5203 \\
\hline $\mathrm{O}$ & 9.5667 & 7.1482 & 1 & 0.7357 & 0.7659 & 0.7554 & 7.5005 \\
\hline $\mathrm{G}$ & 9.6700 & 7.1527 & 1 & 0.7171 & 0.7230 & 0.7173 & 7.4528 \\
\hline Q & 9.2437 & 7.0460 & 1 & 0.7319 & 0.7003 & 0.7242 & 7.5094 \\
\hline
\end{tabular}

$N_{\mathrm{A}}=$ mean number of effective alleles; $N_{\mathrm{E}}=$ number of effective alleles; $P_{\mathrm{A}}=$ number of private alleles; $H_{\mathrm{E}}=$ expected heterozygosities; $H_{\mathrm{O}}=$ observed heterozygosities; $\mathrm{PIC}=$ polymorphism information content; $A R=$ allelic richness.

Table 3 contains genetic variation metrics for the eleven sheep populations. The highest mean number of effective alleles was found in $\mathrm{G}(9.670)$ and $\mathrm{O}$ (9.567), followed by $\mathrm{H}(9.475)$ and $\mathrm{Q}$ (9.244). L had the lowest mean number of effective alleles (8.200). The highest average number of effective alleles was found in L (7.489) and $\mathrm{H}$ (7.475), followed by Ta (7.293) and PD (7.290); the lowest corresponding value was found in Q (7.046). The average number of private alleles was highest in $\mathrm{L}\left(P_{\mathrm{A}}=2\right), \mathrm{H}\left(P_{\mathrm{A}}=1\right)$, and Tibetan sheep $(\mathrm{O}$, $\mathrm{Q}$, and G; average $P_{\mathrm{A}}=1$. The genetic diversity difference index (PIC value) for the whole dataset was high (0.754), and most of the populations had PIC values above 0.750 . Lower 
PIC values were evident in G (0.717), Q (0.724), and L (0.741) sheep, while H and M had PIC values of 0.788 and 0.764 , respectively. The observed heterozygosity averaged over all loci was 0.744 , while the expected heterozygosity was 0.732 . Allelic richness ranged from 7.086 to 7.693 in the eleven populations, and it was higher in Chinese local populations than it was in the non-native sheep populations (Table 3).

\section{Wright's $F$-statistics}

The genetic structure and genetic variation of the sheep populations were analyzed using 26 microsatellite loci and Wright's $F$-statistics. The mean $F_{\text {IT }}$ was 0.175 , the mean $F_{\text {ST }}$ was 0.128 , and the mean $F_{\text {IS }}$ was 0.054 , which indicated that $12.80 \%$ of the total genetic variation came from breed differences, and the remaining $87.20 \%$ came from differences among individuals in each population. $G_{\mathrm{ST}}$ values ranged from 0.013 to 0.248 , while the $N_{\mathrm{m}}$ values among the markers varied from 0.823 to 3.157 ; the mean $G_{\mathrm{ST}}$ was 0.115 and the mean $N_{\mathrm{m}}$ was 1.703 , which indicated that gene flow between populations occurred sometime in the past. The result of variation observed among and within populations of the small number of individuals can be characterized as inbred, while the distribution of the eleven sheep populations was different among the various microsatellite loci $(\mathrm{P}<0.05, \mathrm{P}$ $<0.01$, or $\mathrm{P}<0.001)$ (Table 4).

Table 4. F-statistics for seven Chinese sheep populations and four imported sheep populations at 26 microsatellite loci.

\begin{tabular}{|c|c|c|c|c|c|}
\hline \multirow[t]{2}{*}{ Locus } & \multicolumn{5}{|c|}{ All studied sheep populations } \\
\hline & $F_{\text {IT }}$ & $F_{\mathrm{ST}}$ & $F_{\text {IS }}$ & $G_{\mathrm{ST}}$ & $N_{\mathrm{m}}$ \\
\hline BM6506 & $0.628 * * *$ & $0.191^{* *}$ & $0.540 * *$ & 0.042 & 1.059 \\
\hline OarFCB128 & $0.173 * *$ & $0.124 * *$ & 0.056 & 0.167 & 1.766 \\
\hline OarFCB20 & 0.063 & $0.119 * *$ & -0.064 & 0.013 & 1.851 \\
\hline OarCP34 & $0.254 * *$ & $0.115^{* *}$ & $0.157 *$ & 0.152 & 1.924 \\
\hline BM827 & $0.198 * *$ & $0.154^{* *}$ & 0.049 & 0.248 & 1.373 \\
\hline OarHH35 & $0.119 * *$ & $0.097^{*}$ & $0.103^{*}$ & 0.135 & 2.327 \\
\hline OarJMP8 & $0.437 * * *$ & $0.122 * *$ & $0.359 * *$ & 0.179 & 1.799 \\
\hline BM757 & $0.135 * *$ & $0.131^{* *}$ & 0.005 & 0.037 & 1.658 \\
\hline OarHH41 & $0.140 * *$ & $0.116^{* *}$ & 0.027 & 0.148 & 1.905 \\
\hline OarCP38 & $0.138^{* *}$ & $0.128^{* *}$ & 0.012 & 0.087 & 1.703 \\
\hline HUJ616 & 0.080 & $0.126^{* *}$ & -0.053 & 0.037 & 1.734 \\
\hline ILSTS002 & 0.063 & $0.073^{*}$ & -0.011 & 0.076 & 3.175 \\
\hline RM004 & $0.135 * *$ & $0.124 * *$ & 0.013 & 0.098 & 1.766 \\
\hline MAF65 & $0.116^{*}$ & $0.163 * *$ & -0.056 & 0.052 & 1.284 \\
\hline OarFCB48 & $0.166 * *$ & $0.112 * *$ & 0.061 & 0.167 & 1.982 \\
\hline BM8125 & $0.248 * *$ & $0.121 * *$ & $0.145^{*}$ & 0.185 & 1.816 \\
\hline OarHH47 & $0.131 * *$ & $0.140^{* *}$ & -0.011 & 0.084 & 1.536 \\
\hline OarFCB304 & $0.137 * *$ & $0.119^{* *}$ & 0.020 & 0.150 & 1.851 \\
\hline OarAE119 & $0.114^{*}$ & $0.115 * *$ & -0.001 & 0.087 & 1.924 \\
\hline OMHC1 & $0.350 * *$ & $0.215^{* *}$ & $0.172 *$ & 0.151 & 0.913 \\
\hline OarCP20 & $0.218 * *$ & $0.227^{* *}$ & -0.012 & 0.059 & 0.851 \\
\hline BM1314 & 0.064 & $0.119^{* *}$ & -0.062 & 0.135 & 1.851 \\
\hline CSSM31 & $0.264 * *$ & $0.233^{* *}$ & 0.040 & 0.158 & 0.823 \\
\hline OarJMP29 & $0.109^{*}$ & $0.118^{* *}$ & -0.010 & 0.071 & 1.869 \\
\hline OarVH72 & $0.321 * * *$ & $0.126^{* *}$ & $0.223 * *$ & 0.135 & 1.734 \\
\hline BM6526 & $0.144 * *$ & $0.139 * *$ & 0.006 & 0.147 & 1.549 \\
\hline Total & $0.175^{* *}$ & $0.128^{* *}$ & 0.054 & 0.115 & 1.703 \\
\hline
\end{tabular}

$F_{\text {IT }}=$ wright's F-statistics of inbreeding within total; $F_{\mathrm{ST}}=$ wright's F-statistics of subpopulation within total; $F_{\text {IS }}=$ wright's F-statistics of inbreeding within subpopulation; $G_{\mathrm{ST}}=$ genetic differentiation coefficient; $N_{\mathrm{m}}=$ gene flow; $N_{\mathrm{m}}=0.25\left(1-F_{\mathrm{ST}}\right) / F_{\mathrm{ST}}$. Significance levels of deficit in heterozygotes: $* \mathrm{P}<0.05 ; * * \mathrm{P}<0.01 ; * * * \mathrm{P}<0.001$. 


\section{Phylogenetic analysis}

The genetic distance between populations was analyzed using Nei's standard genetic distance $\left(D_{\mathrm{S}}\right)$. The $D_{\mathrm{A}}$ values between the eleven populations ranged from 0.121 to 0.740 , and $D_{\mathrm{S}}$ values ranged from 0.132 to 0.735 (Table 5). The genetic distance between Q and $\mathrm{O}$ sheep was the smallest $\left(D_{\mathrm{A}}=0.121, D_{\mathrm{S}}=0.138\right)$, and the genetic distance between WS and $\mathrm{H}$ sheep was the largest $\left(D_{\mathrm{A}}=0.740, D_{\mathrm{S}}=0.735\right)$. As expected, the greatest genetic distance was observed between the introduced and the local breeds (Figure 1). The neighbor-joining dendrogram based on Nei's genetic distances divided the eleven sheep populations into two groups. The Ta, M, L, and $\mathrm{H}$ sheep populations clustered in group 1, followed by the Tibetan sheep $(\mathrm{G}, \mathrm{Q}$, and $\mathrm{O})$ populations. The B and $\mathrm{T}$ breeds were clustered in group 2, followed by the WS and PD populations (Figure 1).

Table 5. Nei's genetic distances (above the diagonal) and Nei's standard genetic distances (below the diagonal) for eleven sheep populations.

\begin{tabular}{|c|c|c|c|c|c|c|c|c|c|c|c|}
\hline Population & WS & B & PD & $\mathrm{T}$ & $\mathrm{H}$ & M & $\mathrm{Ta}$ & L & $\mathrm{O}$ & G & Q \\
\hline WS & - & 0.4933 & 0.5918 & 0.4503 & 0.7402 & 0.6812 & 0.6391 & 0.6053 & 0.6415 & 0.6203 & 0.6074 \\
\hline B & 0.4538 & - & 0.4893 & 0.5339 & 0.7059 & 0.6106 & 0.5973 & 0.6207 & 0.6302 & 0.6219 & 0.6363 \\
\hline PD & 0.4756 & 0.3445 & - & 0.5170 & 0.6183 & 0.6073 & 0.5898 & 0.6421 & 0.6398 & 0.6308 & 0.6405 \\
\hline $\mathrm{T}$ & 0.3526 & 0.5804 & 0.4305 & - & 0.5914 & 0.5802 & 0.5344 & 0.5976 & 0.6212 & 0.6091 & 0.5907 \\
\hline $\mathrm{H}$ & 0.7345 & 0.6462 & 0.5833 & 0.5439 & - & 0.2206 & 0.2128 & 0.3507 & 0.4459 & 0.4317 & 0.4417 \\
\hline M & 0.6646 & 0.6054 & 0.5783 & 0.5127 & 0.2778 & - & 0.2093 & 0.4861 & 0.5641 & 0.5423 & 0.5305 \\
\hline $\mathrm{Ta}$ & 0.6378 & 0.5827 & 0.5502 & 0.5085 & 0.2458 & 0.2287 & - & 0.4516 & 0.5027 & 0.5076 & 0.5389 \\
\hline $\mathrm{L}$ & 0.5961 & 0.6077 & 0.6122 & 0.6056 & 0.3308 & 0.4771 & 0.4219 & - & 0.4876 & 0.4801 & 0.4525 \\
\hline $\mathrm{O}$ & 0.6214 & 0.6258 & 0.6303 & 0.6161 & 0.4383 & 0.5807 & 0.5161 & 0.4456 & - & 0.1636 & 0.1209 \\
\hline $\mathrm{G}$ & 0.6120 & 0.6172 & 0.6269 & 0.5982 & 0.4290 & 0.5615 & 0.4981 & 0.4516 & 0.1536 & - & 0.1413 \\
\hline Q & 0.5968 & 0.6211 & 0.6201 & 0.6019 & 0.4186 & 0.5705 & 0.5087 & 0.4381 & 0.1375 & 0.1316 & \\
\hline
\end{tabular}

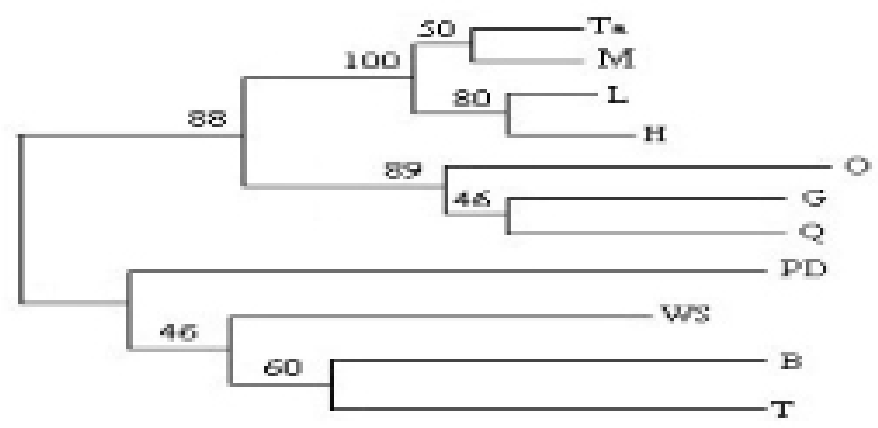

Figure 1. A neighbour-joining dendrogram of 11 mutton sheep populations based on Nei's standard genetic distances (DA).

\section{DISCUSSION}

The average level of genetic diversity in the populations was consistent with reports found in previous studies (Diez-Tascon et al., 2000; Li et al., 2004; Sun et al., 2010). The seven local sheep breeds and the four introduced sheep breeds analyzed in this study are the only native and 
introduced breeds in Gansu Province. Nevertheless, to maintain the breeds and to increase the size of their respective populations, extensive measures have had to be taken. It has been necessary to set up a conservation flock on an experimental farm, as well as a breeding farm, with financial support from the Gansu regional government. Genetic variation values within the above-stated populations and from each breeder's farm are reported in Table 3. The genetic relationships of seven native Spanish breeds were analyzed using the polymorphism of 14 microsatellites to ascertain the utility of molecular coancestry-based methodologies for robust provision of information (Alvarez et al., 2004). Information about a given population's polymorphism and individual heterozygosity can reflect the extent of genetic variation (Botstein et al., 1980). In the present study, the average observed heterozygosity was lower than that previously reported for several Spanish sheep breeds (0.77) (Arranz et al., 2001); this was mainly due to breed differences. The high PIC values obtained for most of the markers attest to the usefulness of PIC values in evaluations of biodiversity for both Chinese local sheep breeds and for the introduced breeds. The PIC value was originally introduced by Botstein et al. (1980). It was used to indicate the value of a marker for polymorphism detection within a population based on the number of detectable alleles and their frequency distribution. The PIC value has been proven to be a generally useful measure of how informative a marker is (Guo and Elston, 1999); the higher the PIC value, the more informative the marker. Populations with similar frequencies at microsatellite loci may still have adaptively important differences that have been maintained by natural selection (Hedrick, 1999). In other cases, populations with different allele frequencies at microsatellite loci may share adaptively important traits.

Differentiation at microsatellite loci should reflect the potential for adaptive differences among populations (Gutiérrez-Espeleta et al., 2000). Arora and Bhatia investigated the genetic diversity and population genetic structure of Indian Muzzafarnagr sheep using 25 microsatellite DNA markers (Arora and Bhatia, 2004). In the present study, within the eleven sheep populations, the genetic diversity in the Chinese local sheep populations was higher than that among the introduced populations. The overall $F_{\mathrm{ST}}$ value for the whole data set was 0.07 higher than the value previously reported by Arranz et al. (Arranz et al., 1998, 2001). However, the present study cannot be directly compared to previous studies on native and introduced sheep breeds because of the different marker sets used. Paired $F_{\mathrm{ST}}$ distances suggested that the introduced and native sheep breeds were the most differentiated populations. The marked deviation from Hardy-Weinberg proportions that were observed for the markers (Table 4) may be explained by null alleles leading to high within-breed $F_{\mathrm{ST}}$ values, which ranged from 0.073 to 0.233 , indicating that $12.80 \%$ of the total genetic variation came from breed differences and the remaining $87.20 \%$ came from differences among individuals in each population.

In general, $G_{\mathrm{ST}}$ allowed for better differentiation among breeds. This was especially true for the sheep breeds that showed high within-breed genetic variability (Table 4$)$. The phylogenetic trees based on Nei's genetic distance $\left(D_{\mathrm{A}}\right)$ and Nei's standard genetic distance $\left(D_{\mathrm{S}}\right)$ were similar. This indicated that the phylogenetic relationships in the eleven sheep populations were not linearly correlated with their geographic distribution. This was in agreement with previous studies that showed that although these populations were originally different, they nonetheless shared genetic material due to natural and artificial selection and different ecological habitats (Ran and Li, 1998). Hedrick and Miller (1992) indicated that populations should be managed so that adequate genetic variability is retained to provide for future adaptation and successful expansion of native and reintroduced free-ranging populations. This is because it is not possible to directly evaluate the biological significance of the genetic differences between locations, and 
genetic differences are roughly proportional to geographic distances. Thus, the most conservative method of selecting stocks for translocation would be to choose the closest available population to preserve local variation and/or potential adaptation (Gutiérrez-Espeleta et al., 2000). The significant levels of genetic divergence between the eleven sheep populations indicated that the heredity of the breeds was affected by historical ecogeographic barriers.

In the present study, in order to test for isolation by distance, $F_{\mathrm{ST}}$ values were plotted against the natural logarithm of pairwise geographic distances among the populations. However, the estimation of genetic differentiation through $F$-statistics was limited. In order to determine whether the degree of scatter shown in the scatter plots increased with geographic distance and whether the populations were in drift-gene flow equilibrium, the residuals from the linear regression of $F_{\mathrm{ST}}$ were correlated with geographic distance. These parameters did not allow for the gene flow patterns among breeds to be ascertained. It has been suggested that the typical high withinpopulation variability of microsatellites may result in a low magnitude in differentiation metrics (Hedrick, 1999; Balloux and Lugon-Moulin, 2002). The $F_{\text {IT }}$ values ranged from 0.063 to 0.628, and $F_{\text {IS }}$ values ranged from 0.005 to 0.540 . No correlation was found, which indicated that there was no relationship between the scatter of pairwise genetic and geographic distances. Therefore, the order of magnitude of the genetic differentiation between breeds assessed using $F_{\mathrm{ST}}$ estimators seemed to be low and rather constant, regardless of the species (MacHugh et al., 1998; Laval et al., 2000). In addition, commonly used estimators of gene flow, such as $N_{\mathrm{m}}=0.25\left(1-F_{\mathrm{ST}}\right) / \mathrm{F}_{\mathrm{ST}}$, are derived on the basis of simplified models for population structure that assume constant population sizes, symmetrical migration at constant rates, and population persistence for time periods long enough to achieve genetic equilibrium, and which indicated that gene flow between populations occurred sometime in the past. These shortcomings highlight the need to apply new, more informative methodologies to ascertain the evolutionary history of present-day populations for both gene flow and recent migration patterns (Wilson and Rannala, 2003). Here, we emphasize the need to apply informative methods to ascertain the evolutionary history of current populations. In addition, we show that methods for estimation of recent migration patterns furnish complementary information, allowing recent introgression processes to be obtained. These results have an important potential application value, and direct significance for future sheep breeding.

\section{ACKNOWLEDGMENTS}

Research supported by the special fund of the National Key Technology R\&D Program (\#2011BAD28B05-1), the Gansu Key Technology R\&D Program (\#201104NKCA083), the Gansu Provincial Science and Technology Key Project (\#1203NKDA023), and the Central Level, Scientific Research Institutes for Basic R\&D Special Fund Business (\#1610322012006).

\section{REFERENCES}

Alvarez I, Royo LJ, Fernández I, Gutierrez JP, et al. (2004). Genetic relationships and admixture among sheep breeds from Northern Spain assessed using microsatellites. J. Anim. Sci. 82: 2246-2252.

Arora R and Bhatia S (2004). Genetic structure of muzzafarnagr sheep based on microsatellite analysis. Small Ruminant Res. 54: 227-230.

Arranz JJ, Bayon Y and San PF (1998). Genetic relationships among Spanish sheep using microsatellites. Anim. Genet. 29: 435-440.

Arranz JJ, Bayon Y and San PF (2001). Differentiation among Spanish sheep breeds using microsatellites. Genet. Sel. Evol. 33: 529-542. 
Azam A, Babar ME, Firyal S, Anjum AA, et al. (2012). DNA typing of Pakistani cattle breeds Tharparkar and Red Sindhi by microsatellite markers. Mol. Biol. Rep. 39: 845-849.

Balloux F and Lugon-Moulin N (2002). The estimation of population differentiation with microsatellite markers. Mol. Ecol. 11: 155-165.

Bindu KA, Raghavan KC and Antony S (2012). Genetic diversity in Malabari goats. Fibre Product. South Am. Camelids Other Fibre Anim. 3: 97-106.

Botstein D, White RL, Skolnick M and Davis RW (1980). Construction of a genetic linkage map in man using restriction fragment length polymorphisms. Am. J. Hum. Genet. 32: 314-331.

Chang ZF, Luo MF, Liu ZJ, Yang JY, et al. (2012). Human influence on the population decline and loss of genetic diversity in a small and isolated population of Sichuan snub-nosed monkeys (Rhinopithecus roxellana). Genetica 140: 105-114.

Colson KE, Brinkman TJ, Person DK and Hundertmark KJ (2012). Fine-scale social and spatial genetic structure in Sitka black-tailed deer. Conserv. Genet. 14: 439-449.

Crawford AM, Dodds KG, Ede AJ, Pierson CA, et al. (1995). An autosomal genetic linkage map of the sheep genome. Genetics 140: 703-724.

d'Angelo FE, Ciani AS, Albenzio M and Ciampolini R (2006). The genetic variability of the Podolica cattle breed from the Gargano area preliminary results. Ital. J. Anim. Sci. 5: 79-85.

Diez-Tascon C, Littlejohn RP, Almeida PA and Crawford AM (2000). Genetic variation within the Merino sheep breed: analysis of closely related populations using microsatellites. Anim. Genet. 31: 243-251.

Gaouar S, Tabet Aoul N, Khaib dit Naib O and Hamouda L (2012). Genetic variability and phylogenetic relationships of ovine Algerian breeds using microsatellites. Forages Grazing Horse Nutr. 129: 52-55.

Guo X and Elston RC (1999). Linkage information content of polymorphic genetic markers. Hum. Hered. 49: 112-118.

Gutiérrez-Espeleta GA, Kalinowski ST, Boyce WM and Hedrick PW (2000). Genetic variation and population structure in desert bighorn sheep: implications for conservation. Conserv. Genet. 1: 3-15.

Hedrick PW and Miller PS (1992). Conservation genetics: techniques and fundamentals. Ecol. Appl. 2: 30-46.

Hedrick PW (1999). Highly variable loci and their interpretation in evolution and conservation. Evolution 53: 313-318.

Hochberg Y (1988). A sharper Bonferroni procedure for multiple test of significance. Biometrika 75: 800-802.

Kantanen J, Olsaker I, Holm LE, Lien S, et al. (2000). Genetic diversity and population structure of 20 North European cattle breeds. J. Hered. 91: 446-457.

Laval G, Iannuccelli N, Legault C, Milan D, et al. (2000). Genetic diversity of eleven European pig breeds. Genet. Sel. Evol. 32: 187-203.

Leroy G, Kayang BB, Youssao IA, Yapi-Gnaore CV, et al. (2012). Gene diversity, agroecological structure and introgression patterns among village chicken populations across North, West and Central Africa. BMC Genet. 13: 34.

Li XL, Gong YF, Zhang JW, Liu ZZ, et al. (2004). Study on polymorphisms of microsatellites DNA of six Chinese indigenous sheep breeds. Yi. Chuan Xue Bao 31: 1203-1210.

MacHugh DE, Loftus RT, Cunningham P and Bradley DG (1998). Genetic structure of seven European cattle breeds assessed using 20 microsatellite markers. Anim. Genet. 29: 333-340.

Ran RJ and Li GL (1998). Discuss on the breeding history for the Wadi sheep. China Sheep Sci. 3: 13-14.

Reynolds J, Weir BS and Cockerham CC (1983). Estimation of the coancestry coefficient: basis for a short-term genetic distance. Genetics 105: 767-779.

Ruane J (1999). A critical review of the value of genetic distance studies in conservation of animal genetic resources. $J$. Anim. Breed. Genet. 116: 317-323.

Sambrook J, Fritsch EF and Maniatis T (1989). Molecular Cloning: a Laboratory Manual, 2nd Edition. NY: Cold Spring Harbor Laboratory Press, Cold Spring Harbor Laboratory, 1659.

Slatkin M and Barton NH (1989). A comparison of three indirect methods of estimating average levels of gene flow. Evolution 43: 1349-1368.

Sun W, Chang H, Tsunoda K, Musa H, et al. (2010). Analysis of geographic and pairwise genetic distances among sheep populations. Biochem. Genet. 48: 376-384.

Taberlet P, Valentini A, Rezaei HR, Naderi S, et al. (2008). Are cattle, sheep, and goats endangered species? Mol. Ecol. 17: $275-284$.

Takezaki N and Nei M (1996). Genetic distances and reconstruction of phylogenetic trees from microsatellite DNA. Genetics 144: 389-399.

Takezaki N, Nei M and Tamura K (2010). POPTREE2: Software for constructing population trees from allele frequency data and computing other population statistics with Windows interface. Mol. Biol. Evol. 27: 747-752.

Wilson GA and Rannala B (2003). Bayesian inference of recent migration rates using multilocus genotypes. Genetics 163 : 1177-1191.

Genetics and Molecular Research 13 (2): 4177-4186 (2014)

CFUNPEC-RP www.funpecrp.com.br 